\title{
Effect of Water Content on Crystalline Structure of Ionic Liquids Mixture Pretreated Microcrystalline Cellulose (MCC)
}

\author{
Qingyue Wang*, Qiyu Chen, Hiroki Niida, Naoki Mitsumura, Takumi Endo \\ Department of Environmental Science and Technology, Graduate School of Science and Engineering, Saitama \\ University, Saitama City, Japan \\ Email: seiyo@mail.saitama-u.ac.jp, chinkeiu2007@yahoo.co.jp
}

Received 17 December 2013; revised 29 January 2014; accepted 21 February 2014

Copyright (C) 2014 by authors and Scientific Research Publishing Inc.

This work is licensed under the Creative Commons Attribution International License (CC BY). http://creativecommons.org/licenses/by/4.0/

(c) (7) Open Access

\begin{abstract}
Microcrystalline cellulose (MCC) was pretreated by using ionic liquids (ILs)-water mixtures solvent with solid acid catalysts. Different amount of water was considerate as the main variable. The peak shift of pretreated sample was determined by FT-IR related to the water content. The XRD was applied to characterize the change in MCC crystalline structure. Thermal decomposition technique was applied to investigate the thermal stability of pretreated MCC. The result indicated that three state of samples were occurred in pretreated MCC sample which was related the amount of water in ILs mixture system. XRD result suggested that the raw sample was distorted and transformed into a less ordered intermediate structure and the smaller crystallite size in lump state sample was obtained which could lead to lower thermal stability. This study revealed the physical chemicals properties, characteristic of molecular structures in MCC using ILs-water mixtures.
\end{abstract}

\section{Keywords}

Microcrystalline Cellulose; Crystallite Structure; Ionic Liquids Mixture; X-Ray Diffractometer; Pretreatment

\section{Introduction}

Microcrystalline Cellulose (MCC), as a steadily renewable native resources, and its derivatives are of great importance. Cellulose and its derivatives as films, fibers, and granules are manufactured by chemical transformations generally include reduction, hydrogenation and dehydration reactions. However, the transformation of

\footnotetext{
${ }^{*}$ Corresponding author.
}

How to cite this paper: Wang, Q.Y., et al. (2014) Effect of Water Content on Crystalline Structure of Ionic Liquids Mixture Pretreated Microcrystalline Cellulose (MCC). Materials Sciences and Applications, 5, 183-192. 
carbohydrate is still a challenge [1]. Development of green technologies for cellulose processing is a topical problem [2].

Pre-dissolution, pretreatment, and extraction process of biomass are the extreme significant steps in the biomass utilization which can affect various substrate characteristics of biomass [3]. Recently, some studies focus on the carbohydrate pretreatment by ionic liquids (ILs) with or without water. The pretreatment processes were most effective in enhancement of cellulose digestibility [4]. The pretreated products were used as raw materials applications in saccharification chemistry [5] [6] and enzymatic hydrolysis [7] [8]. ILs solvents are able to catalyze homogenous hydrous is of cellulose by strong minerals or organic acids [9] [10]. This mixture system could contribute to an innovative process for the large-scale usage of cellulose depolymerization during the pretreatment step [11]. However, water possibly formed hydrogen bonds with both anion and cation of ILs which could cause the overall cohesive energy and lower the viscosity [12]. The role of ILs-water mixtures has recognized only as solvent and anti-solvent since the water could prevent the anion of ILs to generate hydrogen bonds. Therefore, its interpretation and applicability of ILs mixture systems are still under discussion.

A number of lignocelluloses pretreatment studies are being investigated including various chemical, physical or physic-chemical approaches. Common methods for the characterization of MCC crystalline structure are based on X-ray [13] [14], FT-Raman [15], FT-IR [16], NMR [17]. Moreover, thermal decomposition technique is investigated the thermal stability of MCC particles and SEM is used to observe the morphological feature of surface.

This study was aiming to investigate the physical chemicals properties, molecular structures related to crystalline structures in pretreated MCC by using ILs-water mixtures solvent with solid acid catalysts. Different amount of water in the pretreated system was considerate as the main variable. FT-IR presented the important information related to the change of hydrogen bonding during crystalline structures transformation in pretreatment process. XRD was applied to characterize the microcrystalline cellulose crystalline structures, and it could accelerate to understand the variation processing of the MCC crystalline structure. Determination of the crystalline structures, size of crystallites and thermal stability could provide insights into the physical chemistry aspects of ILs-water mixture on MCC at the pretreatment step for a subsequent application.

\section{Experimental and Methods}

\subsection{Materials and Chemicals}

Microcrystalline cellulose powder was supplied by Sigma-Aldrich Co. Ltd., Japan. The ionic liquids, 1-butyl-3methylimidazolium chloride $\left(\mathrm{C}_{8} \mathrm{H}_{15} \mathrm{ClN}_{2}\right.$, [BMIM]Cl), 1-ethyl-3-methylimidazolium chloride $\left(\mathrm{C}_{6} \mathrm{H}_{11} \mathrm{ClN}_{2}\right.$, [EMIM]Cl) and 1-butyl-3-methyl pyrrolidinium chloride $\left(\mathrm{C}_{9} \mathrm{H}_{20} \mathrm{CIN}\right.$, [BMPY]Cl) were purchased from the Wako (Pure Chemical Industries, Ltd, Japan). 1-butyl-3-methylimidazolium tetrafluoroborate $\left(\mathrm{C}_{9} \mathrm{H}_{15} \mathrm{BF}_{4} \mathrm{~N}_{2}\right.$, [BMIM] $\mathrm{BF}_{4}$, purity $\left.\geq 97 \%\right)$ was summarized in Figure 1. Ethanesulfonic acid, polymer Nafion ${ }^{\circledR} \mathrm{NR} 50,(\geq 0.8$ meq/g ion exchange capacity) was purchased from the Sigma-Aldrich Co. LLC.

\subsection{Pretreatment of MCC}

MCC powder was added into a $20 \mathrm{ml}$ flask containing ionic liquids and deionized water with solid acid (Ratio of

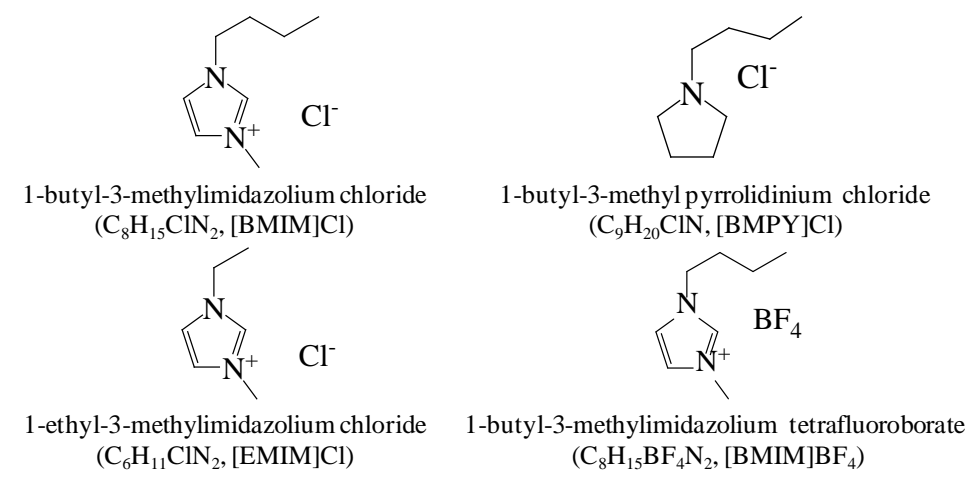

Figure 1. The molecular structure of ionic liquids used in this study. 
MCC/ILs/Nafion ${ }^{\circledR}$ NR50, 1/10/1, w/w; ILs/water was set to molar ratio). Pretreatment experiment was heated and stirred in flask by oil bath at $100^{\circ} \mathrm{C}$ for $1 \mathrm{~h}$. In order to remove the ionic liquid from the pretreated MCC, all the pretreated samples were washed by methanol and deionized water with three times, respectively. The pretreated MCC was filtered on a No. 40 filter paper (Whatman G.E., Co. Ltd.) and dried in oven at $105^{\circ} \mathrm{C}$ for $24 \mathrm{~h}$. The solubility of MCC in ionic liquid has been calculated the Equation (1).

$$
\operatorname{MCCSolubility}(\mathrm{wt} \%)=\left(1-\frac{W_{p}}{W_{i}}\right) \times 100 \%
$$

where

$W_{i}$ : the weight of dried MCC before pretreatment;

$W_{p}$ : the weight of pretreated MCC after dried in oven.

\subsection{Degree of Polymerization (DP)}

Pretreated MCC was dissolved in cupriethylenediamine hydroxide solution. The intrinsic viscosity of the solution was measured by Ubbelodhe viscometer (No.1 Sansyo Co. Ltd., Japan). The value of DP was calculated the Equation (2).

$$
[\eta]=1.67 \times \mathrm{DP}^{0.71}
$$

where

$[\eta]$ is the specific viscosity of dissolved MCC in solution.

\subsection{Fourier Transforms Infrared (FT-IR) Spectrometer Analysis}

Pretreated MCC was analyzed by Fourier transform infrared spectrometer (Model IR-6100, Jasco Co. Ltd., Japan). The ratio of samples and spectroscopic grade $\mathrm{KBr}$ was 1:100; all of the infrared spectra were recorded in absorbance units within the range of $4000-400 \mathrm{~cm}^{-1}$. The peak shift was detected by the Spectrum Manager Ver.2 software (Jason Corporation).

\subsection{X-Ray Diffraction (XRD)}

MCC crystalline structures were analyzed by an Ultima III X-Ray diffractometer (Rigaku Co. Ltd., Japan). $\mathrm{Ni}$-filtered $\mathrm{Cu} \mathrm{K} \alpha$ radiation $(\lambda=0.1542 \mathrm{~nm}$ ) was generated from $40 \mathrm{kV}$ voltage and $40 \mathrm{~mA}$ current. Intensities range was from $10^{\circ}$ to $40^{\circ}$ with $2^{\circ} /$ min scan speed for total X-ray diffraction (XRD) analysis experiment. The crystallite height $002\left(\mathrm{I}_{002}\right)$ and amorphous height $\left(\mathrm{I}_{\mathrm{am}}\right)$ were used to calculate the apparent crystalline index (apparent Cr.I.) and was calculated by Equations (3). The apparent crystallite size $(L)$ of the refection of plane was calculated from the Scherrer equation based on the width of the diffraction patterns Equation (4). The surface chains occupy a layer approximimately $0.57 \mathrm{~nm}$ thick so the proportion of crystallite interior chains is Equation (5), the interlayer distances (d) was calculated by Equation (6).

$$
\text { Cr.I. }=\left(\frac{I_{002}-I_{a m}}{I_{002}}\right) \times 100 \%
$$

The apparent crystallite size $L$ of the refection of plane was calculated from the Scherrer equation based on the width of the diffraction patterns.

$$
\text { Crystallite size } L=\left(\frac{K \times \lambda}{\beta \times \cos \theta}\right)
$$

where,

$K$, the Scherrer constant of value 0.94 ;

$\lambda$, the X-ray wavelength $(0.1542 \mathrm{~nm})$;

$\beta$, the half-height width of the diffraction band;

$\theta$, the Bragg angle corresponding to the planes. 
The surface chains occupy a layer approximimately $0.57 \mathrm{~nm}$ thick so the proportion of crystallite interior chains and the interlayer distances $d$ was calculated as follows:

$$
\text { Crystallite interior chains } X=\left(\frac{L-2 h}{L}\right)^{2}
$$

where,

$L$, the crystallite size for the refection of plane;

$h$, the layer thichkness of the surface chain is $0.57 \mathrm{~nm}$.

$$
\text { Interlayer dis tan ces } d=\left(\frac{\lambda}{2 \sin \theta}\right)
$$

where,

$\lambda$, the X-ray wavelength (0.1542 nm);

$\theta$, the Bragg angle corresponding to the planes.

\subsection{Thermo Gravimetric/Differential Thermal Analysis (TG-DTA)}

MCC sample and pretreated sample were analyzed by the thermo gravimetric/differential thermal analysis (TG-DTA) (Model DTG-60, Shimadzu Co. Ltd., Japan) under the following conditions: about $20 \mathrm{mg}$ of samples were heated at a rate of $10^{\circ} \mathrm{C} \cdot \mathrm{min}^{-1}$ starting from room temperature until $800^{\circ} \mathrm{C}$.

\section{Results and Discussion}

\subsection{Global Impact of MCC Structural Characteristics}

To study the effect of water content on crystallite structure of ionic liquids mixture pretreated MCC, the global impact of MCC structural characteristics after pretreatment was investigated. The solubility of MCC in [BMIM]Clwater mixture was used to understand the state of recovery MCC, the pretreated MCC was characterized via SEM analysis in order to evaluate morphological feature (Date not show). The structural changes of MCC were analyzed based on FT-IR spectra of the MCC sample and pretreated samples.

The solubility of pretreated MCC in [BMIM]Cl-water solvent with solid acid catalyst Nafion ${ }^{\circledR}$ NR50 (NR50) was $5.6 \mathrm{wt} \%$ at $100^{\circ} \mathrm{C}$ in 1 hours with the $1 / 1$ molar ratio of [BMIM]Cl/water, which was most amount of soluble in this mixture system in Figure 2. Dissolution of MCC requires breaking the hydrogen bonds. A group of Rogers have demonstrated that ionic liquid are capable to dissolve the MCC and could enhance the dissolution efficiency with the assistance of microwave heating [18]. However, the water quantity can affect of ionic liquid solubility. The more concentrated of MCC in ionic liquid solution was obtained than that from the sample treated

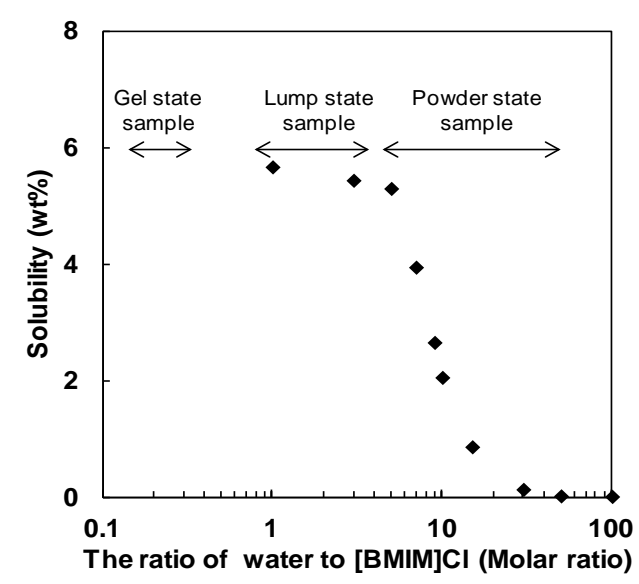

Figure 2. The solubility of MCC using [BMIM]Cl with solid acid and different amount of water ([BMIM]Cl/ water = 1/1-100, molar ratio). 
with water [12]. The amount of MCC dissolved in selected ILs under certain operating conditions is still a topic. It should mention that the goal of this study is not the solubility, but the structural characteristics of recovered MCC. The solid acid catalyst NR50 was used which could obtain solubility increasing and lead to clearly observed characteristics of pretreated MCC.

Three states of samples were occurred in pretreated MCC sample. The powder state sample was no obvious change on morphological feature comparing with MCC samples. Some cracks were found on the surface of the lump state, the phenomenon was due to the breakdown in crystalline structure and physical adhesion. These alterations were attributed to the damage of MCC structures during pretreatment process with the disruption of the structure and a reduction in crystalline which could be meaningful for subsequent application process [19]. This irregular form sample was obtain which was related to adding less water content during pretreatment process comparing with powder stat sample. The regenerate MCC was prepared when no water was added in pretreatment process. The gel sample as the regeneration product has a smooth surface. The regenerate process was considerate that the hydroxyl groups of MCC were replaced by cation of [BMIM]Cl.

The FT-IR spectra of the gel state sample, lump state sample, powder state sample and MCC was presented in Figure 3(a). In the spectrum of the gel state sample, two absorption peaks a, b were observed at $3144 \mathrm{~cm}^{-1}$ and $3079 \mathrm{~cm}^{-1}$. Peak is generally assigned to the $\mathrm{N}-\mathrm{H}$ stretching. Peak c, d was observed at $1263 \mathrm{~cm}^{-1}$ and 1032 $\mathrm{cm}^{-1}$ of the gel state sample which have been assigned to the stretching of $\mathrm{C}-\mathrm{OH}$ in plane at $\mathrm{C} 2$ or $\mathrm{C} 3$ and $\mathrm{C}-\mathrm{O}$ at C6 [20], respectively. Both of the Peak c, d were distinctly weakened comparing the IR spectra of the untreated MCC. These result clearly suggested that the H-bond networks formed in the MCC have been greatly

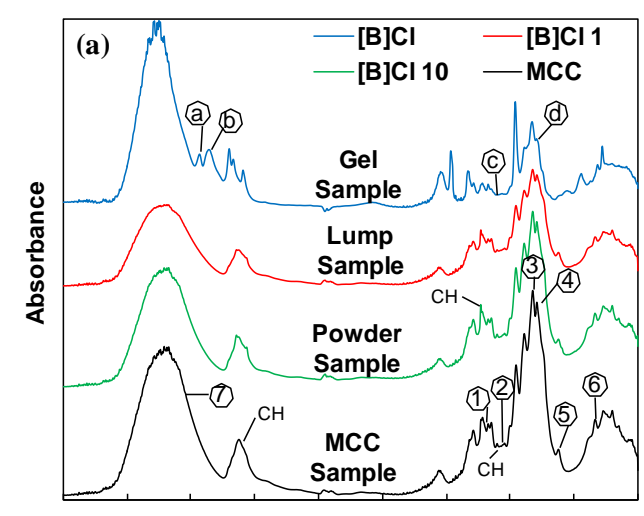

40003600320028002400200016001200800400 Wavelength $\left(\mathrm{cm}^{-1}\right)$

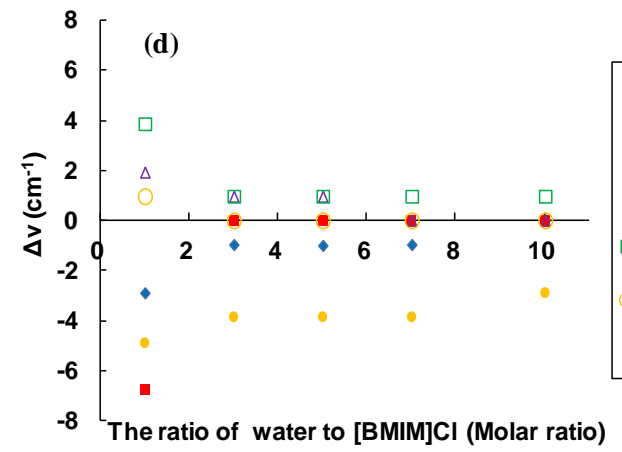

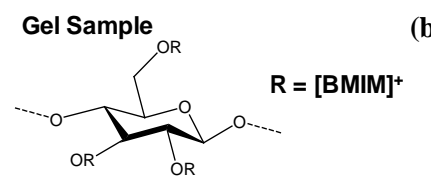

Cellulose Sample

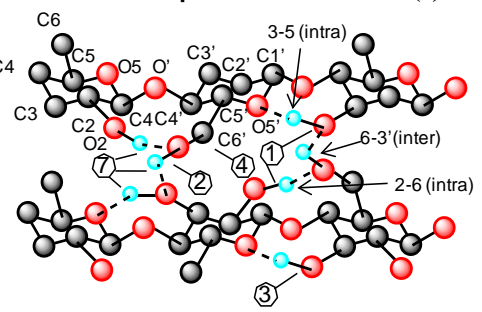

- C-OH out of plane (6) $\left(668 \mathrm{~cm}^{-1}\right)$

- C-O-C,C-C-H at C5 and C6 (5) $\left(898 \mathrm{~cm}^{-1}\right)$

$\rightarrow \mathrm{C}-\mathrm{O}$ at $\mathrm{C} 6$ (4) $\left(1033 \mathrm{~cm}^{-1}\right)$

$\square$ C-O at C3 (3) (1059 $\left.\mathrm{cm}^{-1}\right)$

C-OH at C6 (2) (1235 $\left.\mathrm{cm}^{-1}\right)$

C-OH at C2 or C3 (1) (1341 $\left.\mathrm{cm}^{-1}\right)$

Figure 3. (a) FTIR spectra of gel state sample (sample code [B]Cl, pretreatment condition: $\mathrm{MCC} /[\mathrm{BMIM}] \mathrm{Cl} / \mathrm{NR} 50=1 / 10 / 1$, w/w at $100^{\circ} \mathrm{C}$ for $1 \mathrm{~h}$ ), lump state sample (sample code $[\mathrm{B}] \mathrm{Cl} 1$, pretreatment condition: $\mathrm{MCC} /[\mathrm{BMIM}] \mathrm{Cl} / \mathrm{NR} 50=1 / 10 / 1$, w/w; [BMIM]Cl/ water $=1 / 1$ molar ratio at $100^{\circ} \mathrm{C}$ for $1 \mathrm{~h}$ ), power state sample (sample code $[\mathrm{B}] \mathrm{Cl} 10$, pretreatment condition: MCC/[BMIM]Cl/NR50 = 1/10/1, w/w; [BMIM]Cl/water = 1/10 molar ratio at $100^{\circ} \mathrm{C}$ for $1 \mathrm{~h}$ ) and MCC sample; (b) The possible structural formula of gel sample; (c) The MCC structural and IR band corresponding to the position of molecular structure in MCC; (d) Peak shift of pretreated MCC related the ratio of water to [BMIM]Cl, the wave number of band belong to MCC. 
destroyed in the dissolution process by the [BMIM]Cl solvent. The hydroxyl groups were replaced in the subsequent regeneration processes (Figure 3(b)). The pretreated MCC samples keep its powder state when large amount water used. The lump state sample was observed when the pretreatment condition of [BMIM]Cl/water was set to 1/1 which was present in Figure 3(a). The IR spectra of lump state sample was close to powder state sample. However, there were some irregular cracks found on the surface of the pretreated fond compared to the raw MCC in Figure 3(c). These alterations were attributed to the breakdown of MCC structures during the pretreatment process including intra-molecular hydrogen bonds and the inter-molecular hydrogen bands in MCC molecule chains. This result was considerate to become more susceptible in the subsequent application such as enzymatic hydrolysis [21]. The evidence of this structures damage will be presented below.

In Figure 3, the FT-IR spectra of MCC and pretreated MCC show no obvious differences. Thus, the Spectrum Manager Ver.2 software was used to detect the differences between the peaks. The sample from [B]Cl 1 to $[\mathrm{B}] \mathrm{Cl} 10$ was investigated which was different in the ratio of water to [BMIM]Cl during pretreatment process. The band at $1341 \mathrm{~cm}^{-1}$ (peak 1) and $1235 \mathrm{~cm}^{-1}$ (peak 2) assigned as $\mathrm{C}-\mathrm{OH}$ in plane at $\mathrm{C} 2$ or $\mathrm{C} 3$ and $\mathrm{C}-\mathrm{OH}$ in plane at C6 [22] [23] are shifted to different wave numbers such as $1336 \mathrm{~cm}^{-1}$ and $1236 \mathrm{~cm}^{-1}$, respectively. The band at $1059 \mathrm{~cm}^{-1}$ (peak 3) and $1033 \mathrm{~cm}^{-1}$ (peak 4), assigned as C-O at C3 and C6, respectively [20] [23], is shifted to strength wave number at less water concentration. The band at $898 \mathrm{~cm}^{-1}$ (peak 5) assigned as C-O-C stretching at the $\beta$-(1 $\rightarrow 4)$-glycosidic linkage or C-O-C, C-C-H at C5 and C6 [24] [25] move toward $891 \mathrm{~cm}^{-1}$ by transformation. The FT-IR absorbance change and peak shift of these bending, which arises by changing the environment at MCC molecular hydrogen bands [26].

\subsection{XRD Analysis of Pretreated MCC Crystalline Structure and Size}

The XRD analysis is widely used to evaluate the physic-chemical properties of MCC. The apparent Cr.I was calculated from the ratio of the 002 peak $\left(\mathrm{I}_{002}\right)$ height and the minimum $\left(\mathrm{I}_{\mathrm{am}}\right)$ height. Figure 4 shown the highest peak of 002 peaks was reduced in ILs-water mixture. A clear shallow shoulder peak suggested that the arrangement of MCC chains were disturbed within the hydrogen-banded sheets. Although the reaction occurred in different water content mixture system, the result of these entire pretreated sample suggested that the raw sample was distorted and transformed into a less ordered intermediate structure. The peak in plane 002 of [B]Cl 1 was lowest than that of other sample when water was added in pretreatment process.

In Table 1, the MCC crystalline index (Apparent Cr.I) is the significant crystalline structure parameters. The MCC crystalline index was increased comparing the index of MCC. The result suggests that amorphous MCC was dissolve in mixture system, and then the crystalline MCC was decreased related to the water content in mixture system. The interlayer distance and crystalline size of $d_{101}$ and $d_{101}$ in pretreated sample were increased. The interlayer distance and crystalline size of $\mathrm{d}_{002}$ in pretreated sample were dropped corresponding to amorphous MCC regions diminished, as presented in Table 1.

These results indicated that pretreated sample contain a less ordered structure than untreated one [27]. The $X$ value was used as estimates of the fraction of MCC chains contained in the interior of the crystallites. The pretreated sample showed lower value confirms that MCC chains in a highly organized form in the interior of the MCC crystallite structure could decrease by pretreatment process. This result was reflecting on lower hydrogen bond intensity among neighboring MCC chains.

In Table 2, $L$ is the apparent crystallite size for the refection of plane (002). In Figure 5, the $L$ value was used to describe the crystal lattice of glucose units and the DP value was used to estimates of the length of the MCC chains. This factor combination of result was used in order to obtain overall evaluation the crystallite size in pretreated MCC. The result shown the lower crystal lattice and DP value could existed by ILs-water mixture as characteristic index of recovered MCC. The crystallite size in pretreated MCC was become smaller with overall dimensions. In addition, ionic liquid [BMPY]Cl, [BMIM] $\mathrm{BF}_{4}$ and [EMIM]Cl was validated in this mixture systems. The similar effect was observed in these ionic liquids—-water mixture systems. It concluded that less water used, the smaller crystalline size was obtained in pretreated sample.

\subsection{Thermal Decomposition Analysis of Pretreated MCC Particle Size}

The MCC molecule is a very long polymer of glucose units. The thermal decomposition was tested in order to analyze the thermal stability of pretreated samples. The thermal analysis was done on sample MCC, [B]Cl 1 and $[\mathrm{B}] \mathrm{Cl}$ 10. The weight loose percentage of the pretreated MCC with increasing temperature and the rates of 
(a) Interlayer distances of plane(101) $d_{101}$

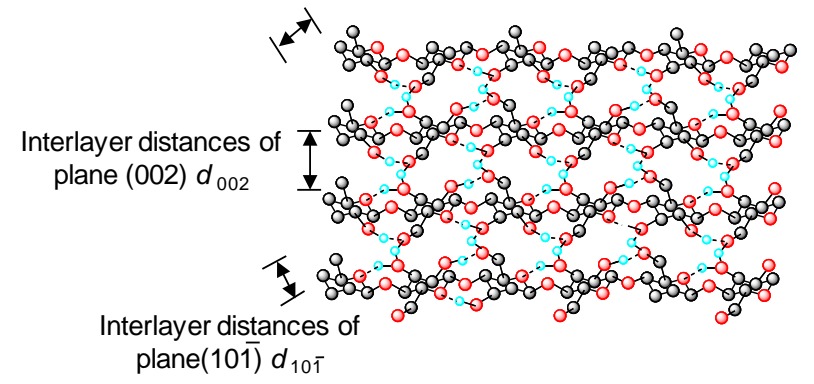

(b)

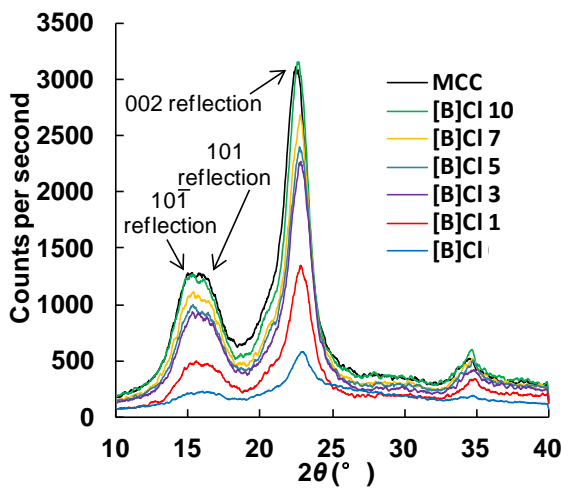

Figure 4. (a) Model used to represent MCC chains; (b) XRD analysis of pretreated samples. (sample code [B]Cl 1, pretreatment condition: MCC/[BMIM]Cl/ NR50 = 1/10/1, w/w; [BMIM]Cl/water $=1 / 1$ in molar ratio at $100^{\circ} \mathrm{C}$ for $1 \mathrm{~h}$; $[\mathrm{B}] \mathrm{Cl}$, $[\mathrm{B}] \mathrm{Cl} 5,[\mathrm{~B}] \mathrm{Cl} 7$ and $[\mathrm{B}] \mathrm{Cl} 10$ was different in the ratio of [BMIM]Cl/water from 1/3 to 1/10 in molar ratio).

Table 1. Parameters obtained from the XRD analysis of pretreated samples (sample code refer to Figure 4).

\begin{tabular}{cccccc}
\hline Sample code & $d_{101}(\AA)$ & $d_{101}(\AA)$ & \multicolumn{3}{c}{002 planes } \\
\cline { 3 - 6 } & & & $d_{002}(\AA)$ & $X$ & $L(\mathrm{~nm})$ \\
\hline MCC & 5.90 & 5.60 & 4.03 & 0.42 & 3.21 \\
{$[\mathrm{~B}] \mathrm{Cl} 1$} & 5.88 & 5.67 & 3.88 & 0.22 & 2.13 \\
{$[\mathrm{~B}] \mathrm{Cl} 3$} & 5.88 & 5.65 & 3.88 & 0.21 & 2.12 \\
{$[\mathrm{~B}] \mathrm{Cl} 5$} & 5.87 & 5.64 & 3.89 & 0.23 & 2.21 \\
{$[\mathrm{~B}] \mathrm{Cl} 7$} & 5.87 & 5.63 & 3.90 & 0.27 & 2.30 \\
{$[\mathrm{~B}] \mathrm{Cl} 10$} & 5.86 & 5.61 & 3.93 & 0.25 & 2.28 \\
\hline
\end{tabular}

Table 2. Parameters obtained from the XRD analysis of pretreated samples related to different ILs with pretreatment condition different in water content; [BMPY]Cl 10: [BMPY]Cl/water = 1/10 molar ratio; [EMIM]Cl 1: [EMIM]Cl/ wa-

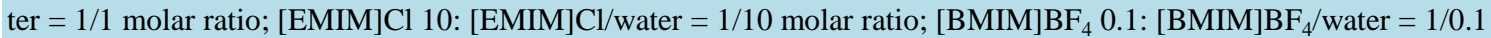

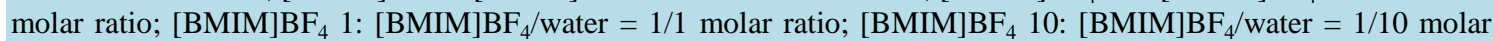
ratio;).

\begin{tabular}{|c|c|c|c|}
\hline & $d_{002}(\AA)$ & $L(\mathrm{~nm})$ & $\mathrm{DP}$ \\
\hline MCC & 4.03 & 3.21 & 210 \\
\hline [B]Cl 1 & 3.88 & 2.13 & 171 \\
\hline [B]Cl 10 & 3.93 & 2.28 & 180 \\
\hline [BMPY]Cl 1 & 3.91 & 2.21 & 154 \\
\hline [BMPY]Cl 10 & 3.94 & 2.28 & 173 \\
\hline [EMIM]Cl 1 & 3.90 & 2.25 & 161 \\
\hline [EMIM]Cl 10 & 3.93 & 2.28 & 176 \\
\hline$\left[\mathrm{BMIM} \mathrm{BF}_{4} 0.1\right.$ & 3.91 & 2.11 & 163 \\
\hline$\left[\mathrm{BMIM} \mathrm{BF}_{4} 1\right.$ & 3.94 & 2.23 & 171 \\
\hline$\left[\mathrm{BMIM} \mathrm{BF}_{4} 10\right.$ & 3.94 & 2.23 & 174 \\
\hline
\end{tabular}


degradation has shown in Figure 6. It was observed that maximum rate of mass loss of sample [B]Cl 1 and [B]Cl 10 exhibited temperature at $365^{\circ} \mathrm{C}$ and $372^{\circ} \mathrm{C}$, respectively, compared that of MCC sample at $368^{\circ} \mathrm{C}$, was present in Table 3.

It was observed that the char left after degradation was $15.2 \%$ for MCC, $10.6 \%$ for $[\mathrm{B}] 1$ and $15.8 \%$ for $[\mathrm{B}] \mathrm{Cl}$ 10 at $800^{\circ} \mathrm{C}$. The $[\mathrm{B}] \mathrm{Cl} 10$ sample has more char than that in MCC. It might be attributed to the fine crystallite size sample in [B]Cl 10 compare with MCC [28]. The thermal decomposition of [B]Cl 10 shifted to higher temperatures with increasing crystalline index. This result can confirm that the amorphous MCC was dissolve in mixture system, and the recovery MCC was containing less part of amorphous MCC. On the other hand, The [B]Cl 1 sample has less char than that in MCC. This result suggested that smaller crystallite size in [B]Cl 1

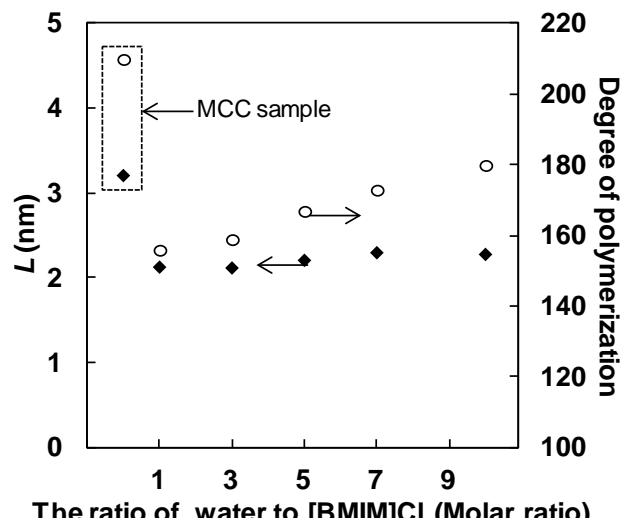

The ratio of water to $[\mathrm{BMIM}] \mathrm{Cl}$ (Molar ratio)

Figure 5. Relationship between $L$ values and degree of polymerization value with the amount ratio of water to [BMIM]Cl (molar ratio).

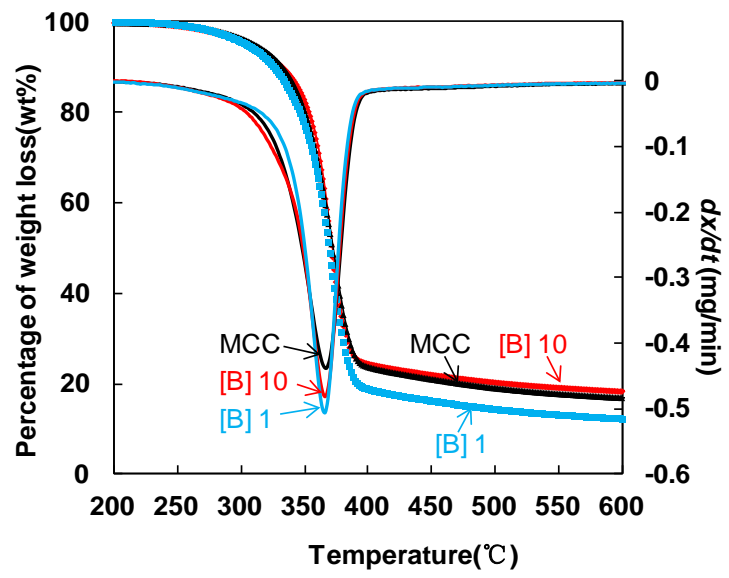

Figure 6. TGA and DTG curves for the different pretreated samples studied.

Table 3. Thermal degradation temperatures, DTG peak and $\%$ residue at $400^{\circ} \mathrm{C}$, $600^{\circ} \mathrm{C}$ and $800^{\circ} \mathrm{C}$ for the pretreated samples under study.

\begin{tabular}{ccccc}
\hline & \multicolumn{3}{c}{$\Delta \mathrm{w}(\mathrm{daf}) / \%$} & \\
\cline { 2 - 4 } Sample code & $400^{\circ} \mathrm{C}$ & $600^{\circ} \mathrm{C}$ & $800^{\circ} \mathrm{C}$ & \\
\hline MCC & 23.3 & 16.9 & 15.2 & 368 \\
\hline [B]Cl 1 & 18.7 & 12.2 & 10.6 & 365 \\
{$[$ B]Cl 10 } & 23.7 & 17.3 & 15.8 & 372 \\
\hline
\end{tabular}


sample than that in MCC [28] [29]. As a result, a less amount of hydrogen bond between neighboring MCC chains resulted from a less order MCC structure which could lead to lower thermal stability, as observed in case of [B]Cl 1 sample.

\section{Conclusions}

1) Three state of samples were occurred in pretreated MCC sample related the amount of water in ILs mixture system. The powder state sample was no obvious change on morphological feature; the lump state samples were found some cracks on its surface; the gel sample as the regeneration product has a smooth surface.

2) The XRD result of pretreated sample suggested that the raw sample was distorted and transformed into a less ordered intermediate structure.

3) The parameters obtained from the XRD analysis of pretreated samples related to different water content had shown that the smaller crystallite size in pretreated MCC was obtained. The crystallite size of MCC was become smaller than the sample which was treated by using more water in ILs-water mixture.

4) The smaller crystallite size in pretreated MCC was also validated in ionic liquid [BMPY]Cl, [BMIM]BF and [EMIM]Cl mixture systems.

5) A less amount of hydrogen bond between neighboring MCC chains resulted from a less order MCC structure. The lump state sample could lead to lower thermal stability and less char content.

\section{Acknowledgements}

Some works of this study were supported by the special funds for Basic Researches (B) (No. 22303022) of Grant-in-Aid Scientific Research of the Japanese Ministry of Education, Culture, Sports, Science and Technology (MEXT).

\section{References}

[1] Olivier-Bourbigou, H., Magna, L. and Morvan, D. (2010) Ionic Liquids and Catalysis: Recent Progress from Knowledge to Applications. Applied Catalysis A: General, 373, 1-56. http://dx.doi.org/10.1016/j.apcata.2009.10.008

[2] Zhu, S.D., Wu, Y.X., Chen, Q.M., Yu, Z.N., Wang, C.W., Jin, S.W., Ding, Y.G. and Wu, G. (2006) Dissolution of Cellulose with Ionic Liquids and Its Application: A Mini-Review. Green Chemistry, 8, 325-327. http://dx.doi.org/10.1039/b601395c

[3] Kohno, Y. and Ohno, H. (2012) Ionic Liquid/Water Mixtures: From Hostility to Conciliation. Chemical Communications, 48, 7119-7130. http://dx.doi.org/10.1039/c2cc31638b

[4] Brandt, A., Ray, M.J., To, T.Q., Leak, D.J., Murphy, R.J. and Welton, T. (2011) Ionic Liquid Pretreatment of Lignocellulosic Biomass with Ionic Liquid-Water Mixtures. Green Chemistry, 13, 2489-2499. http://dx.doi.org/10.1039/c1gc15374a

[5] Li, Q., Jiang, X., He, Y., Li, L., Xian, M. and Yang, J.M. (2010) Evaluation of the Biocompatibile Ionic Liquid 1-Methyl-3-Methylimidazolium Dimethylphosphite Pretreatment of Corn Cob for Improved Saccharification. Applied Microbiology and Biotechnology, 87, 117-126. http://dx.doi.org/10.1007/s00253-010-2484-8

[6] Uju, K.A., Uemura, N., Oshima, T., Goto, M. and Kamiya, N. (2013) Peracetic Acid-Ionic Liquid Pretreatment to Enhance Enzymatic Saccharification of Lignocellulosic Biomass. Bioresource Technology, 138, 87-94. http://dx.doi.org/10.1016/j.biortech.2013.03.147

[7] Ha, S.H., Mai, N.L., An, G. and Koo, Y.M. (2011) Microwave-Assisted Pretreatment of Cellulose in Ionic Liquid for Accelerated Enzymatic Hydrolysis. Bioresource Technology, 102, 1214-1219. http://dx.doi.org/10.1016/j.biortech.2010.07.108

[8] Hou, H.D., Lia, N. and Zong, M.H. (2013) Significantly Enhancing Enzymatic Hydrolysis of Rice Straw after Pretreatment Using Renewable Ionic Liquid-Water Mixtures. Bioresource Technology, 136, 469-474. http://dx.doi.org/10.1016/j.biortech.2013.02.118

[9] Vanoye, L., Fanselow, M., Holbrey, J., Atkins, M.P. and Seddon, K.R. (2009) Kinetic Model for the Hydrolysis of Lignocellulosic Biomass in the Ionic Liquid, 1-Ethyl-3-Methyl-Imidazolium Chloride. Green Chemistry, 11, 390-396. http://dx.doi.org/10.1039/b817882h

[10] Li, C., Wang, Q. and Zhao, Z.K. (2008) Acid in Ionic Liquid: An Efficient System for Hydrolysis of Lignocelluloses. Green Chemistry, 10, 177-182. http://dx.doi.org/10.1039/b711512a

[11] Rinaldi, R., Palkovits, R. and Schüth, F. (2008) Depolymerization of Cellulose Using Solid Catalysts in Ionic Liquids. Angewandte Chemie International Edition, 47, 8047- 8050. http://dx.doi.org/10.1002/anie.200802879 
[12] Mazza, M., Catana, D.A., Vaca-Garcia, C. and Cecutti, C. (2009) Influence of Water on the Dissolution of MCC in Selected Ionic Liquids. Cellulose, 16, 207-215. http://dx.doi.org/10.1007/s10570-008-9257-x

[13] Nishiyama, Y., Langan, P. and Chanzy, H. (2002) Crystal Structure and Hydrogen-Bonding System in Cellulose I $\beta$ from Synchrotron X-Ray and Neutron Fiber Diffraction. Journal of the American Chemical Society, 124, 9074-9082. http://dx.doi.org/10.1021/ja0257319

[14] Nishiyama, Y., Sugiyama, J., Chanzy, H. and Langan, P. (2003) Crystal Structure and Hydrogen Bonding System in Cellulose I $\alpha$ from Synchrotron X-Ray and Neutron Fiber Diffraction. Journal of the American Chemical Society, 125, 14300-14306. http://dx.doi.org/10.1021/ja037055w

[15] Schenzel, K., Fischer, S. and Brendler, E. (2005) Cellulose New Method for Determining the Degree of Cellulose I Crystallinity by Means of FT Raman Spectroscopy. Cellulose, 12, 223-231. http://dx.doi.org/10.1007/s10570-004-3885-6

[16] Oh, S.Y., Yoo, D.I., Shin, Y.S., Kim, H.C., Kim, H.Y., Chung, Y.S., Park, W.H. and Youk, J.H. (2005) Crystalline Structure Analysis of Cellulose Treated with Sodium Hydroxide and Carbon Dioxide by Means of X-Ray Diffraction and FTIR Spectroscopy. Carbohydrate Research, 340, 2376-2391. http://dx.doi.org/10.1016/j.carres.2005.08.007

[17] Larsson, P.T., Hult, E.L., Wickholm, K., Pettersson, E. and Iversen, T. (1999) CP/MAS 13C-NMR Spectroscopy Applied to Structure and Interaction Studies on Cellulose I. Solid State Nuclear Magnetic Resonance, 15, 31-40.

[18] Swatloski, R.P., Spear, S.K., Holbery, J.D. and Rogers, R.D. (2002) Dissolution of MCC with Ionic Liquids. Journal of the American Chemical Society, 124, 4974-4975. http://dx.doi.org/10.1021/ja025790m

[19] Tan, H.T., Lee, K.T. and Mohamed, A.R. (2011) Pretreatment of Lignocellulosic Palm Biomass Using a Solvent-Ionic Liquid [BMIM]Cl for Glucose Recovery: An Optimisation Study Using Response Surface Methodology. Carbohydrate Polymers, 83, 1862- 1868. http://dx.doi.org/10.1016/j.carbpol.2010.10.052

[20] Kačuráková, M., Smith, A.C., Gidley, M.J. and Wilson, R.H. (2002) Molecular Interactions in Bacterial MCC Composites Studied by 1D FT-IR and Dynamic 2D FT-IR Spectroscopy. Carbohydrate Research, 337, 1145-1153. http://dx.doi.org/10.1016/S0008-6215(02)00102-7

[21] Lee, S.H., Voherty, T.V., Linhardt, R.J. and Dordick, J.S. (2009) Ionic Liquid-Mediated Selective Extraction of Lignin from Wood Leading to Enhanced Enzymatic Cellulose Hydrolysis. Biotechnology and Bioengineering, 102, 1368-1376. http://dx.doi.org/10.1002/bit.22179

[22] Cael, J.J., Gardner, K.H., Koenig, J.L. and Blackwell, J. (1975) Infrared and Raman Spectroscopy of Carbohydrates. Paper V. Normal Coordinate Analysis of Cellulose I. Journal of the Chemical Society, 62, 1145-1153. http://dx.doi.org/10.1063/1.430558

[23] Colom, X. and Carrillo, F. (2002) Crystallinity Changes in Lyocell and Viscose-Type Fibres by Caustic Treatment. European Polymer Journal, 38, 2225-2230. http://dx.doi.org/10.1016/S0014-3057(02)00132-5

[24] Ruan, D., Zhang, L., Mao, Y., Zeng, M. and Li, X. (2004) Microporous Membranes Prepared from Cellulose in $\mathrm{NaOH} /$ Thiourea Aqueous Solution. Journal of Membrane Science, 241, 265-274. http://dx.doi.org/10.1016/j.memsci.2004.05.019

[25] Cao, Y. and Tan, H. (2004) Structural Characterization of Cellulose with Enzymatic Treatment. Journal of Molecular Structure, 705, 189-193. http://dx.doi.org/10.1016/j.molstruc.2004.07.010

[26] Chen, Q., Wang, Q., Mitsumura, N. and Niida, H. (2013) Improved Cellulose by Ionic Liquid Mixture with Solid Acid Catalysis and Its Application in Polyethylene Glycol Liquefaction. Materials Sciences and Applications, 4, 839-845. http://dx.doi.org/10.4236/msa.2013.412107

[27] Cheng, G., Varanasi, P., Arora, R., Stavila, V., Simmons, B.A., Kent, M.S. and Singh, S. (2012) Impact of Ionic Liquid Pretreatment Conditions on Cellulose Crystalline Structure Using 1-Ethyl-3-Methylimidazolium Acetate. The Journal of Physical Chemistry B, 116, 10049-10054. http://dx.doi.org/10.1021/jp304538v

[28] Das, K., Ray, D., Bandyopadhyay, N.R. and Sengupta, S. (2010) Study of the Properties of Microcrystalline MCC Particles from Different Renewable Resources by XRD, FTIR, Nanoindentation, TGA and SEM. Journal of Polymers and the Environment, 18, 532-538. http://dx.doi.org/10.1007/s10924-010-0167-2

[29] Poletto, M., Pistor, V., Zeni, M. and Zattera, A.J. (2010) Crystalline Properties and Decomposition Kinetics of MCC Fibers in Wood Pulp Obtained by Two Pulping Processes. Polymer Degradation and Stability, 96, 679-685. http://dx.doi.org/10.1016/j.polymdegradstab.2010.12.007 